\title{
Selected concepts on ethics in biopharmaceutical innovation
}

\begin{abstract}
We are at a time where diseases, epidemics and viruses spreading with unlimited rate and neither young nor elderly individuals have escaped from it. At a time when the average of chronic patients, epidemic, disabled and mortality is increasing day after day, this dilemma pushed and motivated the biopharmaceutical sectors to innovation in order to mitigate this plight. giving birth to a new bio drug need to pass through several phases, and every phase should pass through several ethical guidelines and some responsibilities, according to the rational and moral principle the pharmacists, stakeholders, the managers and the whole company crew form a team with different specialization but with one principle, is to serve the patients' health, improve the healthcare system and enhance the humanity wellbeing with a high ethical and responsibility values. This article gives a glance about some ethical standards, behavior and responsible guidelines which should the whole biopharmaceutical crew adhere to before and during and after the bio drug innovation's process.
\end{abstract}

Keywords: biopharmaceutical innovation, ethics, pharmacists, stakeholders, drug
Volume 6 Issue 4 - 2017

\author{
Kadour Ghanemi,' Shuangsheng Yan² \\ 'Department of Business Management, School of International \\ Pharmaceutical Business, China Pharmaceutical University, China \\ ${ }^{2}$ Department of Social Science, School of International \\ Pharmaceutical Business, China Pharmaceutical University, China
}

Correspondence: Shuangsheng Yan, Department of Social Science, International Pharmaceutical Business School China Pharmaceutical University, No 639, Longmian Avenue, Jiangning District, Nanjing, China, Tel +86 I33 051517 82,

Email yss@cpu.edu.cn

Received: November 20, 2017 | Published: December 29, 2017

\section{Introduction and ethics in biopharmaceutical innovation paradigms}

Responsible research and innovation (RRI) is among the most important issues that have generated a huge debate within the political and social milieu, which became an overall case for the biggest EU Research and innovation program ever Horizon. ${ }^{1}$ Responsible research and innovation is among the important doctrines for the sustainability of the company. ${ }^{2}$ Ethics and the biopharmaceutical responsible innovation is a paradigm of a sector where the ethics and responsibility of health professionals is inevitably linked to public and private life. The biopharmaceutical research, development and marketing responsibilities are taken by the pharmacists, directors and managers of the biopharmaceutical company, all are a combined healthcare team which work together and have a lot of combined bio drugs innovation's issues. ${ }^{3}$ Now we are in age where the bio pharmacy improves with a high rapidity, a new generation of several bio drugs is discovered for improving survival rates, a lot of chronic and even fatal maladies are promised now with a new series of bio drugs to enhance the patient health. ${ }^{4-7}$ The role of this staff (bio pharmacists, directors, and managers) is to minimize the risks and the harm of the new developed bio drugs during the clinical trials process and during the patient's consumption of this new treatment, also to secure the efficacy of the new bio drug and guarantee that the novel discovered bio drugs can be used safely. Moreover, to facilitate its access and also to strengthen the country's economy in order to serve the humanity interests and boosting the healthcare progress in general. ${ }^{8}$ However, the biopharmaceutical innovation can be seen as a junction between business and health, this gives rise to a several series of ethical and responsibility issues and a dire need to make some rules, standards and principles for the bio drug innovation's process built on rational and virtues.

\section{Ethics in biopharmaceutical innovation paradigms}

There are several ethical issues concerning the biopharmaceuticals innovation, according to the US food and drug administration (FDA), before the bio drugs get promoted and reach the open market it should firstly pass through several stages, every stage is bounded by a set of responsibilities and ethical standards and guidelines.

\section{The selection of developing bio drug}

Frequently before selecting the bio drug, the bio pharmacists can come across a number of ethical issues and responsibilies, research staff should firstly know if the bio drug which they are innovating really deserve and worth to put such a big budget and lab effort, usually the physicians would like to dedicate their research to give birth a new bio drug which can make a change and an amelioration in the patient's health and they wish the efficacy of this new treatment, otherwise it would be a waste of money, time and effort. In other side they are not glad when they are required to work on a bio drug that gives a low advances to the company, for instance the (me-too) bio drugs (similar to another existing bio drug but just belong to the same treatment category and treat the same kind of malady but their formulation, posology, composition and the cure conditions and rapidity might be different), however, this kind of bio drugs sometimes can maintain the reputation of the bio drug market, for example in case of the expiration of the patent is in the near future, patenting a (me-too) bio drug is the best choice for the bio drug company for keeping the good price, because if the bio drug losses its patent, the company might encounter an income decreasing. ${ }^{9}$ One of the causes which make the bio pharmacists do not like to develop metoo bio drugs is that they do a lot of work and devote a huge budget to develop this bio drugs to get just a small and tiny benefits, it can lead to a financial losses and lack of benefits. On the other hand, the patients get convenient benefits related with the drop of the bio drugs prices, because of the competition and the variety of medicines, this difference of interests creates a conflict between the society benefits and the company benefits, which make the company side think negatively before starting select the bio drug to develop. Moreover, whatever the case before selecting the bio drug to innovate, the company managers and the pharmacists and the stakeholders should 
firstly think about the serious disease and epidemic which exists in the poor and developing countries, and the lack of access to the bio drugs. The biopharmaceutical community should focus on serving the society and the public in concentrating their efforts on innovating and developing more bio drugs to enhance the public health and reassure the needed bio drug regardless the personal benefits, because this is a responsibility and ethical standards which every biopharmaceutical staff should consider, because the social responsibility is higher than everything. ${ }^{10}$

\section{Human and nonhuman (Animals) use ethics}

In tracing the ethical issues in the clinical trials, the new bio drugs should be tested in nonhuman and in human samples, in case of using the animals in the clinical trials, it exists some associations and federations for instance the animal liberation associations and the European Union political platform and its Scientific Committee which forbid the use of this animals in the clinical trials, considering that as giving pain and torture to the animals and also to protect the animal from extinction. Moreover, consider its use in the clinical tests as irresponsible and unethical behavior. ${ }^{11-13}$ In contrast, in case of using the human sample during doing clinical tests, this should be based on the handling way between the physicians, patients, the ethical standards and the method of merging them into each other, because distinctly should have a huge combination between the clinical ethics and the physician's profession. Physicians must be highly ethical and firstly build their relationship with patients based on patient's interests whatever the case, also they should always put the patient benefits in the first position. ${ }^{14}$

Usually the clinical research is based on ethics and rational standards which serve the public benefits, and not only serve a special interest which can only consider the private benefits, if it is built on a private interest in this case it is considered as a selfishness and unethical behavior.

There are several methods to characterize the ethical rules and standards, including three basic ones: it should serve the patient's interest first, do not give damage and injury and pain to the patient and respecting his choice and attitude to this research. ${ }^{15}$ The use of human sample in the clinical tests has received a big attention and concern in the healthcare sector and in the public, different foundation, association and political organization gives birth to several ethical and responsible standards to ensure that the human being will be treated under the ethical and responsible norms.

\section{Risk versus benefits}

Before starting the clinical research on the human subject, the bio pharmacists should firstly take in consideration the risks versus benefits issues, they initiate in assess and estimate the benefits and the harms potential of this research, and make a nearly comparison to see if the interest average exceeds the damage average, the harm which can affect the patient should be a moderate and reasonable harm comparing to the benefits which can be gained. ${ }^{16}$ According to the declaration of HELSINKI (DOH is a set of ethical principles regarding human experimentation developed for the medical community by the world medical association), every medical research can contain some risks, but this does not mean that the physicians should not pay attention to that, researchers should be competent on doing this kind of research practice, they should take a big consideration of this burdens and try to minimize this risks as much as possible. ${ }^{17}$ The physicians should keep controlling and assessing these risks, also should not initiate and start doing the clinical research till they are sure that the resulted harms are less than the benefits and that harms can be managed and handled. Furthermore, in case that the harms are exceeding the benefits potential, physicians must do assess whether they can continue this research or doing some modification or even stop this research. ${ }^{18}$ In this way, the research staff is abiding to the rational and ethical standards of avoiding harm which is considered as basic rules of any research.

\section{Compliance and adherence to the clinical research protocols}

The design of the study research protocols should be closely strict and rigorous in order to have a good scientific data and correct output, in order to conserve the patient's benefits, behind every efficient and successful research therapy an adherence to research protocols, in case of the absence or non-adherence to this protocols, lack of caution or any information or technical error, can lead to an unfavorable and disadvantages outcomes also can expose the human subject to risks, complex his disease, reduce the therapy trial efficacy chances, decrease the human subject's life quality and even can lead him to death. ${ }^{19-21}$ Moreover, the bad adherence can complicate the research process and give rise to several difficulties which push the clinicians and researchers to do additional processes, therefore, wasting of time and efforts also huge financial losses. ${ }^{22,23}$

There has been an extreme controversial about this lack of compliance and many papers have been published in regard to the non-adherence, in 1999 at the human gene therapy institute of Pennsylvania (Penn) university, during a test of gene treatment, due to non-compliance with experiment protocols, Jesse Gelsinger a patient of 18years old died, the investigations affirmed that the cause of the death was due to the deficiency and shortage of vigilance and infringement of the research protocols, the clinicians did not follow the research protocols as required. ${ }^{24-26}$ From these evidences we understand that any protocol's violation is considerably unethical can lead to bad consequences.

\section{Affordability and compound pricing}

Bio pharmaceutical companies spend a huge sums for giving birth to a new bio drug to the market, the estimated amount is more than $800 \$$ (at the time of publishing this information), ${ }^{27}$ followed by new statistics exceeded the imaginary amounts, where for the one new bio drug, the expenditure is approximately reaching the 1,8billion US dollars, ${ }^{28}$ most companies make this large expense as a reason and excuse to raise the price of the new treatment in order to attempt the compensation and recover the money spent in this new compound innovation process, too many people around the world are struggling to get access and afford to the needed therapy. Because of the lack of this novel therapeutics, sometimes people are forced to see at their patients dying in front of their eyes. Developing and developed countries neither have escaped from this dilemma, this impasse affect more and more the developing and poor countries, often this new bio drugs prices are so high, and it is the insurance who pay for it, but how about the persons who have no insurance for covering and afford this treatment? A lot of Americans uninsured are facing several challenges and difficulties for getting the necessitated therapy, regrettably they have no choice just believing that it is impossible to reach and afford the cost of this treatment, ${ }^{29}$ this lead to increase the severity of their disease or even to drive them to death.

Due to the inability and lack of sustainability and obtainment of the needed bio drugs, the raise of mortality rate, spreading of diseases and epidemics in the developing and poor countries is increasing day 
after day, for instance the disease that terrifies people in sub-Saharan Africa, the cardiovascular and hypertension illness, too much people are in great suffering for the inability to reach this disease therapy, ${ }^{30}$ high pricing is the major trouble which almost sicker are facing, it creates a big problem for the health care system in general, another example of the new hepatitis $\mathrm{C}$ virus (HCV) medicines in several countries and in the low- and middle-income countries in particular is unaffordable because of its extreme high price, ${ }^{31}$ therefore can lead to a serious consequences.

In the United States, due to the catastrophic increases in the price of cancer treatment, the cancer patients are in a state of confusion and in great distress, many of them cannot access to the treatment because of its exaggerated high price, those who have an advanced cancer disease, can lose hope of continue the therapy and even can reach the death because the price of treatment is overstretched. ${ }^{32}$

All of this evidences refers to the need for intervention by international organizations specialized in this field to legalize and put a rational limit and rules to reduce this problem, this dilemma has created a huge controversy among the affected community and in the health field in general, it is ethical from the companies to provide patients those who cannot afford the drug with treatment or help them to get an insurance in order to cover the cost of the therapy needed, whether in poor countries or in developed countries, also it would be a superior conduct's sort if they create a program of assistance to patients and put a roofing price laws to the novel therapeutics, so that everyone can access to it. Thus, developing treatments will serve the patient and give him benefits and enhances their health not only serve the interest of the company and strengthen its financial treasury, because it is a kind of selfishness and inhumanity if the company does not care about the patients' health conditions.

\section{Conclusion}

Nowadays, the distinction of the biopharmacy innovation is totally noticeable than it was previously, we are now in an age where the bio pharmacy has become a double-edged sword, on the one hand serving the private interests and on the other hand serving the public interests, this gives birth to a kind of conflicts. Trying to make a rational and reasonable balance between the needs of individual patients with those of the company without affecting the patient's wellbeing is a sophisticated professional practice, research staff and sponsors should uphold their professional integrity and practice their profession under a moral and responsible way in giving the priority to the patients benefits, during deciding an action course, they should use their vocational judgment in condition that those decisions was built on ethical rational standards and rules. Pharmacists make sure that they are in line with the responsible and ethical standards of the profession because the healthcare system is in dire need of a robust and rigorous ethical infrastructure in order to enhance the patient health and develop the healthcare system and stop the disease spread to serve the common good in general, solemn ethics education it might be the key to insert the ethical awareness and the responsibility tendency in the healthcare community and integrate a high ethical standards in the researcher's mind, the need of learning and the knowledge is the effective way and method to change and control the ethical measuring and dimension of the profession.

\section{Acknowledgements}

We acknowledge the Jiangsu Overseas Research \& Training Program for University Prominent Young \& Middle-aged Teachers. Kadour Ghanemi is the recipient of a full scholarship from the China Scholarship council.

\section{Conflict of interest}

The authors declare that there is no conflict of interest.

\section{References}

1. Von Schomberg Rene. A vision of responsible innovation. In: Owen R, Heintz M, et al. editors. Responsible Innovation. London: John Wiley, forthcoming; 2013. p. 51-74.

2. Ghanemi K, Yan S. Companies and Responsible Innovation: Toward a Long-Term Success. MOJ Public Health. 2017:6(4).

3. Dessing R, Flameling. Ethics in pharmacy: a new definition of responsibility. J Pharm World Sci. 2003;25(1):3-10.

4. Siyanbola WO. Academia-Industry Interactions in Nigeria Pharmaceutical Innovation System. Procedia-Social and Behavioral Sciences. 2012;52:279-289.

5. Halim N, J Doyle. DR1 Public Health Innovation: Biopharmaceuticals Lost in Translation? Value in Health. 2012;15(4):A6.

6. Kadour Ghanemi, Shuangsheng Yan. Biopharmaceutical Innovation: Benefits and Challenges. Open Access Journal of Science. 2017;1(1):4.

7. Ghanemi K, Yan S. Biopharmaceutical Innovation Responsibility and Ethical Use of Placebo. MOJ Immunol. 2017;5(6):1- 7.

8. Eaton, Margaret L. Ethical Issues Associated with Pharmaceutical Innovation. In: Hanekamp, editor. Business Ethics of Innovation. Germany: Springer; 2007. p. 39-62.

9. Dimasi JA, Paquette C. the economics of follow-on drug research and development: trends in entry rates and the timing of development. Pharmacoeconomics. 2004;22(2 Suppl 2):1-14.

10. Hartog R. Essential and non-essential drugs marketed by the 20 largest European pharmaceutical companies in developing countries. Social science \& Medicine. 1993;37(7):897-904.

11. Tucker G, DeSilva B, Dressman J, et al. Current Challenges and Potential Opportunities for the Pharmaceutical Sciences to Make Global Impact:An FIP Perspective. J Pharm Sci. 2016;105(9):2489-2497.

12. Prescott MJ. Ethics of primate use. Adv Sci Res. 2010;5(1):11-22.

13. Russell, Wiliam MS, Burch, et al. The principles of humane experimental technique. London: Methuen; 1959.

14. Doukas DJ. Returning to professionalism: the re-emergence ofmedicine's art. Am J Bioeth. 2004;4(2):18-19.

15. Brody H. The Ethics of Drug Development and Promotion: The Need for a Wider View. Medical Care. 2012;50(11):910-912.

16. Kimmelman J. "Valuing Risk: The Ethical Review of Clinical Trial Safety." Kennedy Institute of Ethics Journal. 2004;14(4):369-393.

17. Carlson RV, Boyd KM, Webb DJ. The revision of the Declaration of Helsinki: past, present and future. British Journal of Clinical Pharmacology. 2004;57(6):695-713.

18. World Medical Association. Declaration of Helsinki. 1964.

19. Cleemput I, Kesteloot K. Economic implications of non-compliance in health care. Lancet. 2002;359:2129-2130.

20. Burrell CG, Levy RA. Therapeutic consequences of noncompliance. Improving patient compliance: proceedings of a symposium. Reston, VA7 National Pharmaceutical Council, 1984:7-16.

21. Shiovitz TM, Bain EE, Mc Cann DJ. Mitigating the Effects of Nonadherence in Clinical Trials. Journal of Clinical Pharmacology. 2016;56(9):1151-1164.

22. Flanagan A, Gartenmann T, Lovich D, et al. Boston Consulting Group. The hidden epidemic: finding a cure for unfilled prescriptions and missed doses. USA; 2003. 
23. Lewis A. Non-compliance: a $\$ 100$ billion problem. Remington Rep 1997;5:14-15.

24. Sibbald B. Death but one unintended consequence of gene-therapy trial. CMAJ: Canadian Medical Association Journal. 2001:1641-1612.

25. Food and Drug Administration (FDA). Notice of opportunity for hearing In: James Wilson MD, editor. USA: Institute for Gene therapy, University of Pennsylvania; 2002.

26. Wilson JM. Lessons learned from the gene therapy trial for ornithine transcarbamylase deficiency. Mol Genet Metab. 2009;96(4):151-157.

27. DiMasi JA. New drug development in the united states 1963-1999. Clinical pharmacology \& therapeutics. 2001;69(5):286-296.

28. Todorović Z, Protić D. Bioethical issues in the development of biopharmaceuticals. Filozofija I Društvo. 2012;23(4):49-56.
29. Johnson L. U.S. Public Interest Research Group. Paying the price: The high cost of prescription drugs for uninsured Americans. USA: U.S. PIRG; 2004.

30. Cappuccio FP, Miller MA. Cardiovascular disease and hypertension in sub-Saharan Africa:burden, risk and interventions. Intern Emerg Med. 2016;11(3):299-305.

31. Iyengar S, Tay-Teo K, Vogler S, et al. Prices, Costs, and Affordability of New Medicines for Hepatitis C in 30 Countries: An Economic Analysis. PLOS Medicine. 2016:13(1).

32. Kantarjian H. High Cancer Drug Prices in the United States: Reasons and Proposed Solutions. Journal of Oncology Practice. 2014;10(1):208-211. 